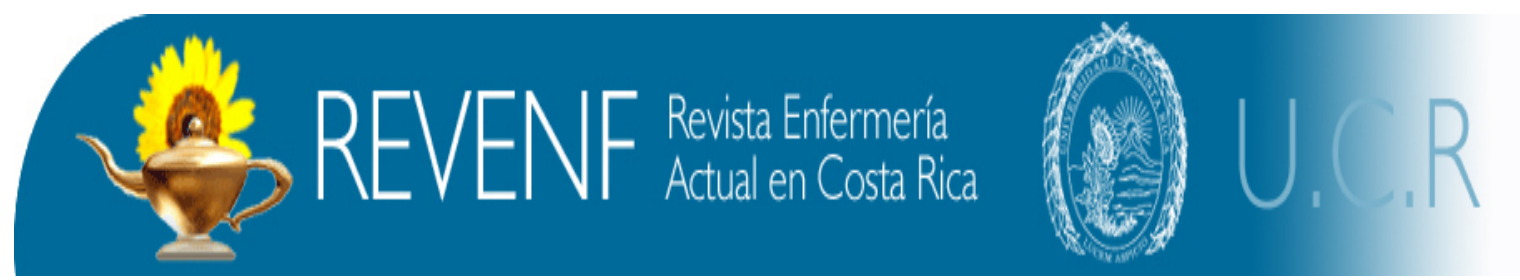

REVISTA SEMESTRAL - No. 11 Año 5 Set. 2006 - Mar. 2007

ISSN $1409-4568$

\title{
EL PROFESIONAL DE ENFERMERÍA DOCENTE DE LA ESCUELA DE ENFERMERÍA DE LA UNIVERSIDAD DE COSTA RICA Y SU ACTIVIDAD EN INVESTIGACIÓN ${ }^{1}$
}

\section{Ernestina Aguirre Vidaurre ${ }^{2}$}

\begin{abstract}
RESUMEN
El presente ensayo es una reflexión sobre el quehacer del profesional de Enfermería docente de la Escuela de Enfermería de la Universidad de Costa Rica y su actividad en investigación, así como el panorama actual en este campo. El objetivo de este ensayo es evidenciar como la investigación ha estado incorporada en la labor docente de Enfermería y su efectividad en el desarrollo disciplinar. Se realizó una revisión de la investigación reciente que han realizado los y las docentes, donde se refleja que cumplen con las características fundamentales. En la primera parte del ensayo se realiza una introducción, luego se plantea la investigación desde su desarrollo histórico, posteriormente se presenta el panorama actual y se presentan conclusiones.
\end{abstract}

Palabras claves: Docente, Investigación, Escuela de Enfermería, Universidad de Costa Rica 


\section{INTRODUCCION}

El vínculo entre el contexto social y laboral con la salud es una característica que relaciona de manera directa a la Enfermería con los procesos de investigación. en ese contexto. Sin ese conocimiento ni vivencia con el entorno social, ambiental y laboral, no es posible explicar ni encontrar regularidades en la salud y calidad de vida de las poblaciones.

Esta peculiaridad hace que en el proceso de formación de Enfermería en la Universidad de Costa Rica, se tome en cuenta para relacionar y establecer la correspondencia directa con la docencia, la acción social y la investigación las realidades sociales. De esta manera, la docencia en la profesión se halla articulada con la investigación, y las prácticas del grupo estudiantil, impartidas por estos docentes de ningún modo constituyen aplicaciones mecánicas de lo aprendido.

El requisito imprescindible para el desarrollo de la práctica es el conocimiento de las necesidades existentes en personas y poblaciones e introducirlos para el desempeño en labores de atención y capacitación.

\section{DESARROLLO DE LA INVESTIGACIÓN}

Las docentes que han desarrollado la investigación a partir de su práctica, han constatado la efectividad de tales procesos, por lo tanto, deben contribuir con esta información al cuerpo de conocimiento de la Enfermería, disciplina en constante desarrollo. Lo anterior, responde a un probado interés por trabajar en equipo ${ }^{3}$, por escuchar $y$ tener respuestas rápidas ${ }^{4}$; además de poseer una capacidad negociadora y consensual, afabilidad y energía.

Además, otro aspecto que contribuye es el reconocimiento de la trayectoria histórica de la enseñanza de Enfermería desde sus inicios en Costa Rica en el siglo XIX hasta la incorporación a la Universidad de Costa Rica; institución que ha sido para la profesión fuente de la modernización y desarrollo, y por sus criterios de calidad y excelencia, trabajo compartido $\mathrm{y}$ solidario, gestión ética y ejecutiva, calidez humana y capacidad de negociación.

\section{PANORAMA ACTUAL}

Las labores de investigación desarrolladas en las prácticas de la docencia, deben ser apreciadas y consideradas como tales por la administración universitaria., es decir debe dársele la ponderación laboral y académica como una actividad investigativa. $^{5}$

A pesar de que la investigación que realizan los y las docentes en la Escuela de Enfermería de la Universidad de Costa Rica posee las características fundamentales, la universidad no cumple

\footnotetext{
${ }^{3}$ En los trabajos finales de graduación que realiza la Unidad académica participan tanto docentes de otras escuelas de la Universidad de Costa Rica como profesionales de Enfermería que laboran en otras instituciones de salud del país.

${ }^{4}$ La Unidad académica elabora proyectos de investigación como respuesta a necesidades y problemas encontrados en los Diagnósticos Situacionales de los escenarios donde se realizan las prácticas clínicas.
} 
con lo que establece la política 2.11: “ $L a$ Universidad asignará recursos para fortalecer la investigación en aquellas sedes universitarias o unidades académicas donde la investigación tenga un menor grado de estimulo," (Consejo Universitario, 2006)

La investigación es en las prácticas una actividad colectiva, en donde estudiantes, docentes y la población intervienen activamente. Sin embargo, la responsabilidad recae en la profesora tutora o profesor tutor que en algunos casos es el o la investigadora principal en los trabajos de los y las estudiantes. ${ }^{6}$ Ésta responsabilidad no es reconocida para la docente $\mathrm{o}$ el docente investigador o investigadora, quien como docente, conduce, asesora y supervisa la práctica de la investigación.

Por otra parte, el tiempo asignado a los y las docentes para asesorar las investigaciones en los trabajos finales de graduación ha sido insuficiente, porque tienen que dedicarle tiempo extra clase, debido a que el tiempo asignado (carga académica) es insuficiente ${ }^{7}$; incrementándose esta situación debido a la particularidad de la profesión, por ejemplo:

$\checkmark$ Se trabaja con personas y, para las personas.

$\checkmark$ Se debe dar al estudiantado, la capacitación previa sobre culturas, modo de vida, actitudes, creencias

\footnotetext{
${ }^{5}$ En los trabajos finales de graduación modalidad seminario el docente puede proponer el tema a la Comisión de trabajos finales de graduación de la Unidad Académica.

${ }^{6}$ De acuerdo con el Reglamento de Carga Académica para la asesoría de los Trabajos Finales de Graduación se asigna horas por semana.
}

de la población con la que se va a trabajar $^{8}$.

$\checkmark \quad$ En las investigaciones la modalidad que domina son las prácticas dirigidas ${ }^{9}$.

$\checkmark \quad$ Las investigaciones se llevan a cabo en todos los lugares del país, lo que genera que los y las docentes asesoras de estos trabajos se tengan que desplazar para evaluar su ejecución, y generalmente lo hacen fuera de horario de clases. ${ }^{10}$

${ }^{8}$ Implementación de un programa de atención integral en salud, dirigido a las (os) lideres indígenas de Talamanca, febrero 1999“Experiencias cognitivas y practicas de las parteras empíricas en la atención brindada a la mujer en el embarazo, parto y puerperio en los diversos cantones de Costa Rica en el I semestre de 1999

${ }^{9}$ Implementación de un programa de atención integral en salud reproductiva orientado a alumnos de IV grado de la escuela de Barrio San Roque de Liberia, primer semestre de 1999. Programa de enfermería obstétrica para la prevención de amenaza de parto prematuro en el escenario familiar Hospital México 2000

${ }^{10}$ Implementación de un programa de atención integral en salud reproductiva orientado a alumnos de IV grado de la escuela de Barrio San Roque de Liberia, primer semestre de 1999. La atención en salud mental bajo el enfoque de atención integral que brinda el personal de salud en el primer nivel de atención en el cantón de Siquirres, primer semestre de 1999. Características sociales, biológicas, ambientales y políticas que influyen en la incidencia de hepatitis A, en el cantón de Coto Brus, II semestre de 1998. Taller de capacitación dirigida a niños de tercero y cuarto grado de las escuelas suscritas al área en la promoción y conservación del ecosistema con copépodos y olominas para el control de Aedes aeqypti en Chacarita de Puntarenas, II semestre, 1999. Implementación del Departamento de Salud Laboral en la Hacienda La Luisa 3.A. Sarchí, Alajuela. Creación de una clínica especializada en la atención de enfermería para usuarios portadores de heridas en el Hospital Monseñor Sanabria, Puntarenas, 2001 
De las investigaciones que se realizan en la Escuela de Enfermería, la mayoría causa impacto, esto ha generado que tanto, directores y directoras de Enfermería, educadores y educadoras en servicio en los hospitales y autoridades de instituciones en salud han implementado las propuestas presentadas.

Participación de las docentes en la formulación de las políticas, programas de gobierno con grupos específicos como niños y niñas del CEN-CINAI, adolescentes en los Centros de estudios, adultos en los Centros de trabajo, indígenas en Talamanca y, adultos mayores tanto en los centros hospitalarios como en los centros diurnos, entre otros aspectos.

\section{CONCLUSION}

La peculiaridad de la enseñanza de la Enfermería no es compatible con las formas como la administración de la Escuela y la Universidad consideran las investigaciones que realizan los y las docentes.

La visión tradicional que se tiene de la investigación en el ámbito académico, ha impedido que la investigación vinculada a la docencia en Enfermería, pueda tener una trascendencia e impacto en la formación de los profesionales; además, no se aprovecha su aporte al desarrollo y difusión de los conocimientos en la colectividad científica nacional o internacional.
No se dispone de suficiente tiempo asignada dentro de la carga académica regular ni de recursos que permitan sistematizar las experiencias académicas.

En la práctica docente se han acumulado saberes, conocimientos de técnicas validas de Enfermería que aún están sin publicar.

Es necesario reconceptualizar la práctica de Enfermería, conjugando los esfuerzos de formación y de gestión para actuar de una forma unida, tomando la investigación como eje integrador para la producción de nuevos conocimientos y modelos. Lo anterior permite visualizar la Enfermería como una disciplina que potencia la salud del pueblo costarricense.

\section{BIBLIOGRAFÍA}

-Álvarez, Juan y Jurgenson Gayou.(2003). ¿Cómo hacer investigación cualitativa?. México, D. F.: Editorial Paidós.

-Coffey, Amanda y Paul Atkinson.(1996). Encontrar los sentidos a los datos cualitativos Editorial Universidad de Antioquia.

-Comisión de Investigación (2002) Primera Jornada de Investigación .Escuela de Enfermería Universidad de Costa Rica.

-Comisión de Investigación (2004) Segunda Jornada de Investigación.Escuela de Enfermería Universidad de Costa Rica.

-Consejo Universitario (2005) Políticas de la Universidad de Costa Rica para el 2006. Impresión del SIEDIN.

-Gálvez T , Alberto (2001) Enfermería basada en la Evidencia. Madrid: Editorial Index.

-Hernández, Roberto y otros. (1998) Metodología de la investigación. México, D.F.: Editorial McGraw Hill.

-Hernández, J. M. y otros. (2003). Fundamentos de la Enfermería Madrid: Editorial Mc Graw-Hill Mckerman.J.(1999).Investigación-Acción y currículo. Madrid.: Editorial Morata.

-Valles, Miguel.(1997) Técnicas Cualitativas de Investigación social Barcelona: Editorial Síntesis. - Vega, V Nora Agnes(2004) Informe Anual de la Comisión de Investigación. Escuela de Enfermería Universidad de Costa Rica. 
